\title{
Naringin protects rat lung against the doxorubicin- induced biochemical injury
}

\begin{abstract}
Doxorubicin is an anthracycline group of antibiotics, which finds it use in the treatment of several malignancies. The use of doxorubicin not only kills neoplastic cells but also affects normal cells, which hampers its efficient use in patients. Therefore, any agent that can reduce the toxicity of doxorubicin will be useful in clinical conditions. Naringin a dietary flavanone present in citrus fruit has been investigated for its protective action against the doxorubicin-induced oxidative stress in albino rats. The albino rats were intraperitoneally administered with $2 \mathrm{mg} / \mathrm{kg}$ body weight of naringin or $5 \mathrm{mg} / \mathrm{kg}$ body weight of doxorubicin alone or in combination with each other. The activities of glutathione-s-transferase, catalase and superoxide dismutase were estimated at different post-treatment times. Simultaneously, glutathione contents were also measured at different post-doxorubicin treatment times. Administration of doxorubicin alone caused a time dependent but significant reduction in the activities of glutathione-s-transferase, catalase and superoxide dismutase and glutathione concentration. The administration of rats with naringin before doxorubicin administration significantly raised the activities of glutathione-s-transferase, catalase and superoxide dismutase activities and glutathione concentration in the lungs. Our study indicates that naringin arrested the doxorubicin-induced oxidative stress by increasing the antioxidants status in the lungs of rats.
\end{abstract}

Keywords: doxorubicin, naringin, rat, lung, antioxidants
Volume 5 Issue 2 - 2018

\author{
Ganesh Chandra Jagetia, Lalrinpuii T \\ Department of Zoology, Mizoram University, India
}

Correspondence: Ganesh Chandra Jagetia, 10 Maharana Pratap Colony, Sector- | 3, Hiran Magri, Udaipur-3 | 3002, India, Tel 9436352849,Email gc.jagetia@gmail.com

Received: February 02, 2018 | Published: April 16, 2018

\section{Introduction}

Since the isolation of doxorubicin (DOX) in 1960s from Streptomyces peucetius it has emerged as one of the most effective anticancer drugs for the treatment of cancer. ${ }^{1,2}$ Doxorubicin has been used clinically since 1970 s, for the treatments of several malignant tumours including myeloblastic leukemias, lymphomas, breast cancer, small cell lung cancer, ovarian cancer, childhood solid cancers and soft tissue sarcomas. ${ }^{3-5}$ The doxorubicin also finds its utility in the treatment of liver cancers. ${ }^{6}$ Recent phase I clinical trial has reemphasized the application of doxorubicin in conjunction with lurbinectedin (PM01183) as a useful paradigm in the treatment of patients presenting with small cell lung cancer. ${ }^{7}$

One of the important drawbacks of clinical use of doxorubicin is the development of life threatening cardiomyopathy both in adults as well as children who receive it as a part of cancer treatment regimen. ${ }^{8-10}$ Multiple mechanisms are responsible for the development of cardiotoxicity in the patients receiving doxorubicin for cancer treatment. One of the most important and predominant mechanisms by which doxorubicin induces cardiomyopathy is the production of oxygen free radicals in the mitochondria of cells and the presence of iron further increase this effect. ${ }^{9,11-13}$ The doxorubicin generates redox active quinone-hydroquinone- containing anthracyclines, that undergo one-electron and two-electron reduction by a wide variety of reducing agents which may be chemical and/or enzymatic. ${ }^{14-18}$ This process leads to the formation of semiquinone free radicals and/or other reactive species that trigger antitumor activity either by alkylating DNA, or by causing breaks in the DNA strand or by initiating lipid peroxidation. ${ }^{19}$ The induction of additional oxidative stress by doxorubicin may not be neutralized by endogenous system and introduction of exogenous antioxidants may be a prudent strategy to mitigate the doxorubicin-induced oxidative stress.
Naringin is a dietary flavonoid abundantly produced as secondary metabolite by various citrus fruits including Citrus paradise, Citrus nobilis, Artemisia selengensis, Citrus junos, Citrus sinensis, Citrus unshiu, Citrus tachibana, Artemisia stolonifera, roots of Cudrania cochinchinensis, aerial parts of Thymusherba barona, fruits of Pon cirus and other citrus species. ${ }^{20}$ Naringin has been reported to act as an antiviral, anticancer, hepatoprotective, cardioprotective and neuroprotective agent in several preclinical studies. ${ }^{21-25}$ It has been found to possess free radicals scavenging, metal chelating and antioxidant properties. ${ }^{26-34}$ Naringin has been reported to protect against the radiation and doxorubicin-induced chromosome damage earlier. ${ }^{30,35,36}$ It has been found to protect against doxorubicin-induced cardiotoxicity in vitro and in vivo. ${ }^{37}$ Naringin has been reported to reduce incidence of benzo-a-pyrene-induced forestomach carcinoma in mice..$^{38}$ It has also been found to protect against the iron-induced toxicity in vitro and in vivo. ${ }^{31,38}$ Naringin acts as an antidiabetic, antifibortic, anti-inflammatory, antidyslipidemic antiosteoporotic agent and protected against lipodystrophy and cognitive damages. ${ }^{39-42}$ It has been reported to be cytotoxic against breast cancer and HeLa cells and effective in the treatment of Walker's carcinoma in rats. ${ }^{43-45}$ Naringin has been reported to protect against the doxorubicin-induced cardiotoxicity without compromising with its antitumor activity in mice. ${ }^{24}$ The effect of naringin on the doxorubicin-induced lung toxicity has been not studied, therefore, the present study was undertaken to obtain an insight into the effect of naringin against doxorubicininduced oxidative damage in the lungs of albino rats.

\section{Materials and methods}

\section{Chemicals}

Doxorubicin hydrochloride (Biochem Pharmaceutical Industries, Mumbai, India) was procured from a local supplier, whereas naringin 
was purchased from Acros Organics Ltd, Geel, Belgium. Cacodylic acid, diethylenetriaminepentaacetic acid, ethylenediaminetetraacetic acid, nitroblue tetrazolium, 5,5-dithio2-nitrobenzoic acid, phenozine methosulphate, NADH, trichloroacetic acid, glutathione (reduced), and 1-chloro,2,4-dinitrobenzene were supplied by Sigma Chemicals Co, St. Louis, MO, USA. Potassium dihydrogen phosphate, disodium hydrogen phosphate, hydrogen peroxide, dipotassium hydrogen phosphate, pyrogallol and other routine chemicals were procured from Merck India Ltd., Mumbai, India.

\section{Animal handling}

The guidelines issued by the World Health Organization, Geneva Switzerland and the INSA (Indian National Science Academy, New Delhi, India) were strictly followed during animal care and handling. Usually six to eight weeks old male albino rats weighing 45-60 grams procured locally, were kept in the polypropylene cages in the controlled conditions of temperature and light $(12 \mathrm{~h}$ of light and dark each). The study was approved by Institutional Animal Ethics Committee (IAEC) of Mizoram University, Aizawl, India.

\section{Preparation of drugs and mode of administration}

Doxorubicin hydrochloride and naringin were freshly dissolved in sterile double distilled water, immediately before use. The animals received either $0.01 \mathrm{ml} / \mathrm{g}$ body weight (b. wt.) naringin or doxorubicin intraperitoneally.

\section{Experimental}

The animals were divided into the following groups to study the antioxidant action of naringin in the rat lung:

a. Control: The animals were injected intraperitoneally with distilled water

b. Naringin: Animals received $2 \mathrm{mg} / \mathrm{kg} \quad$ b. wt. naringin intraperitoneally. ${ }^{35}$

c. Doxorubicin: This group of animals was administered with $5 \mathrm{mg}$ $\mathrm{kg}$ b. wt. of doxorubicin intraperitoneally. ${ }^{32}$

d. Naringin + Doxorubicin: The animals of this group were administered with $2 \mathrm{mg} / \mathrm{kg}$ b. wt. naringin intraperitoneally once daily consecutively for three days. One hour after the last administration of naringin, $5 \mathrm{mg} / \mathrm{kg}$ b. wt. of doxorubicin was administered intraperitoneally. ${ }^{32}$

The animals from all the groups were killed by cervical dislocation at $1 / 2,1$ and 2 hours post doxorubicin administration. The animals were dissected and perfused with ice cold saline transcardially.

\section{Preparation of homogenate}

The lungs of the animals were surgically removed blot dried, weighed and $10 \%$ homogenate was prepared in phosphate buffered saline for the estimation of glutathione, glutathione-s-transferase, catalase, and superoxide dismutase.

\section{Total proteins}

The protein contents were determined using the modified method of Lowry.

\section{Glutathione}

The amount of glutathione was determined as described earlier. ${ }^{46}$ In brief, proteins in the homogenate were precipitated by $25 \%$ TCA, and centrifuged. The supernatant was collected transferred into another tube. It was mixed with $0.2 \mathrm{M}$ sodium phosphate buffer $(\mathrm{pH} 8.0)$ and $0.06 \mathrm{mM}$ DTNB. The whole mixture was incubated for 10 minutes at room temperature. The absorbance of the sample/s was read against the blank at $412 \mathrm{~nm}$ in a UV-VIS double beam spectrophotometer (Shimadzu Corporation, Tokyo, Japan) and the GSH concentration has been calculated from the standard curve.

\section{Glutathione-S-transferase}

Glutathione-S-transferase (GST) was determined as described earlier. ${ }^{47}$ Briefly, the lung homogenate was mixed with $0.1 \mathrm{M}$ potassium phosphate buffer, $1 \mathrm{mM}$ EDTA, glutathione reductase, and $10 \mathrm{mM}$ GSH, $12 \mathrm{mM}$ tert-butyl-hydroperoxide. The resultant mixture was incubated for $10 \mathrm{~min}$ at $37^{\circ} \mathrm{C}$ in a water bath. The absorbance was read against the blank at $340 \mathrm{~nm}$ using a double beam UV-VIS spectrophotometer.

\section{Catalase}

The catalytic reduction of hydrogen peroxide was used as a measure of catalase activity as described earlier. ${ }^{48}$ In brief, the samples were mixed with hydrogen peroxide and incubated at $37^{\circ} \mathrm{C}$. The decomposition of hydrogen peroxide was monitored every 30 seconds by recording the absorbance against the blank at $240 \mathrm{~nm}$ using a UVVIS double beam spectrophotometer.

\section{Superoxide dismutase}

Total SOD activity, was determined by the pyrogallol autooxidation method. ${ }^{49}$ Briefly, the samples were mixed with $62.5 \mathrm{mM}$ triscacodylic acid buffer, containing $1 \mathrm{mM}$ diethylenetriaminepentaacetic acid. This was followed by the addition of $4 \mathrm{mM}$ pyrogallol. The autooxidation of pyrogallol was monitored against the blank at 420 $\mathrm{nm}$ using a UV-VIS double beam spectrophotometer.

\section{Statistical Analysis}

The significance between the treatments was determined using the Student's ' $t$ ' test. A $p$ value of $<0.05$ was considered statistically significant. The Solo 4 Statistical Software (BMDP Statistical Software Inc, Los Angeles, CA, USA) was used for statistical analyses.

\section{Results}

The results are shown as mean \pm standard error of the mean in Figure 1-4.

\section{Glutathione}

The spontaneous glutathione concentration in lungs of nondrug treated control albino rats was estimated as $25.6 \pm 0.8 \mathrm{nmol} / \mathrm{mg}$ protein. Administration of $2 \mathrm{mg} / \mathrm{kg} \mathrm{b}$. wt. of naringin treatment did not alter the GSH concentration significantly in the lungs of rats when compared to control. Doxorubicin treatment resulted in a significant decline in the GSH concentration as early as $0.5 \mathrm{~h}$ post treatment, which was approximately 2.5 folds lower than the spontaneous GSH concentration (Figure 1). The GSH concentration continued to decline with assay time and almost 4 and 6 -fold reduction in the GSH concentration was observed at 1 and $2 \mathrm{~h}$ post- doxorubicin treatment, respectively in the lungs of rats treated with $5 \mathrm{mg} / \mathrm{kg} \mathrm{b}$. wt. doxorubicin alone (Figure 1). The pattern of decline in the GSH concentration in naringin+doxorubicin treated group was exactly 
similar to that of DOX treatment alone (Figure 1). However, the naringin treatment prior to doxorubicin administration resulted in a significant rise in the GSH concentration in the rat lung at 1 and 2 $\mathrm{h}$ post-doxorubicin-treatment times when compared to doxorubicintreatment alone (Figure 1).

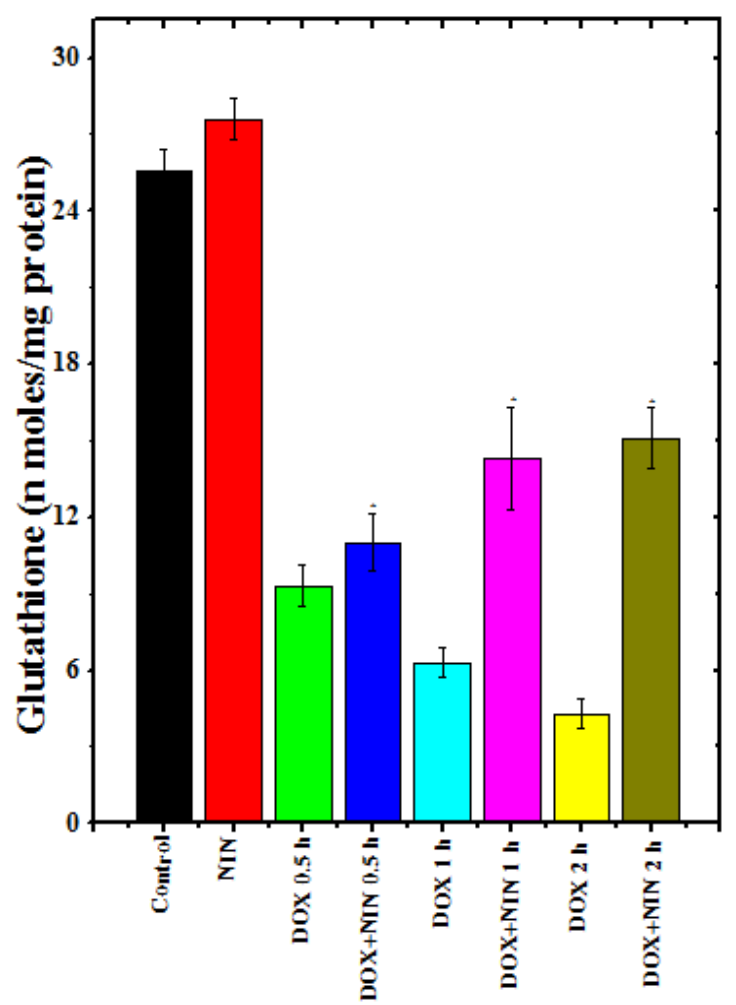

Figure I Alteration in the doxorubicin-induced attrition in the glutathione concentration in the rat lung by naringin $\mathrm{p}<0.01$.

\section{Glutathione-S-transferase}

The glutathione-s-transferase activity of non-drug treated control rat lungs was $0.9 \pm 0.11 \mathrm{nmol} / \mathrm{mg} /$ protein and naringin treatment alone did not alter the spontaneous glutathione-s-transferase activity significantly as compared to control. Doxorubicin treatment caused a significant decline in the GST activity, which was 1.5 -fold lower than the control activity at $0.5 \mathrm{~h}$ post- doxorubicin -treatment (Figure 2). Increase in assay time resulted in a further attrition in the GST activity and it was 1.8 -fold lower at $1 \mathrm{~h}$ post-doxorubicin treatment and reduced by an almost 2.25 -fold at $2 \mathrm{~h}$ post-doxorubicin treatment than the non-drug treated control. Naringin treatment significantly raised the GST activity at all post-doxorubicin-treatment times in the naringin+doxorubicin group when compared to doxorubicin treatment alone. However, a maximum increase of 2.8 -fold was observed at $2 \mathrm{~h}$ post- doxorubicin-treatment (Figure 2).

\section{Catalase}

The spontaneous catalase activity in the control rat lung was found to be $24 \pm 1 \mathrm{nmol} / \mathrm{mg}$ protein and naringin treatment did not alter the spontaneous catalase activity significantly (Figure 3 ). The administration of doxorubicin into rats resulted in a significant decline in the catalase activity at all post-doxorubicin-treatment assay times as compared to control (Figure 3). The doxorubicin treatment caused approximately 2 -fold depletion in the catalase activity at all postdoxorubicin-treatment times when compared to spontaneous catalase activity. Naringin treatment before doxorubicin administration increased the catalase activity at all post-treatment times (Figure 3). However, this rise was significant only at $1 \mathrm{~h}$ post doxorubicin treatment.

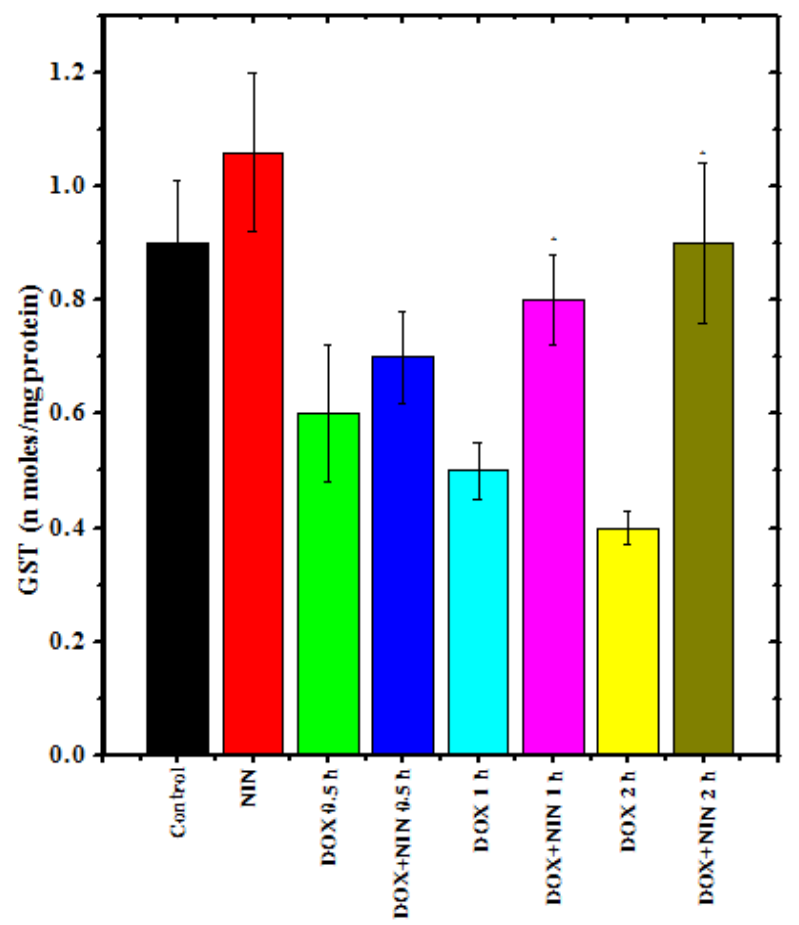

Figure 2 Alteration in the doxorubicin-induced decline in the glutathione-stransferase activity in the rat lung by naringin $\mathrm{p}<0.0 \mathrm{I}$.

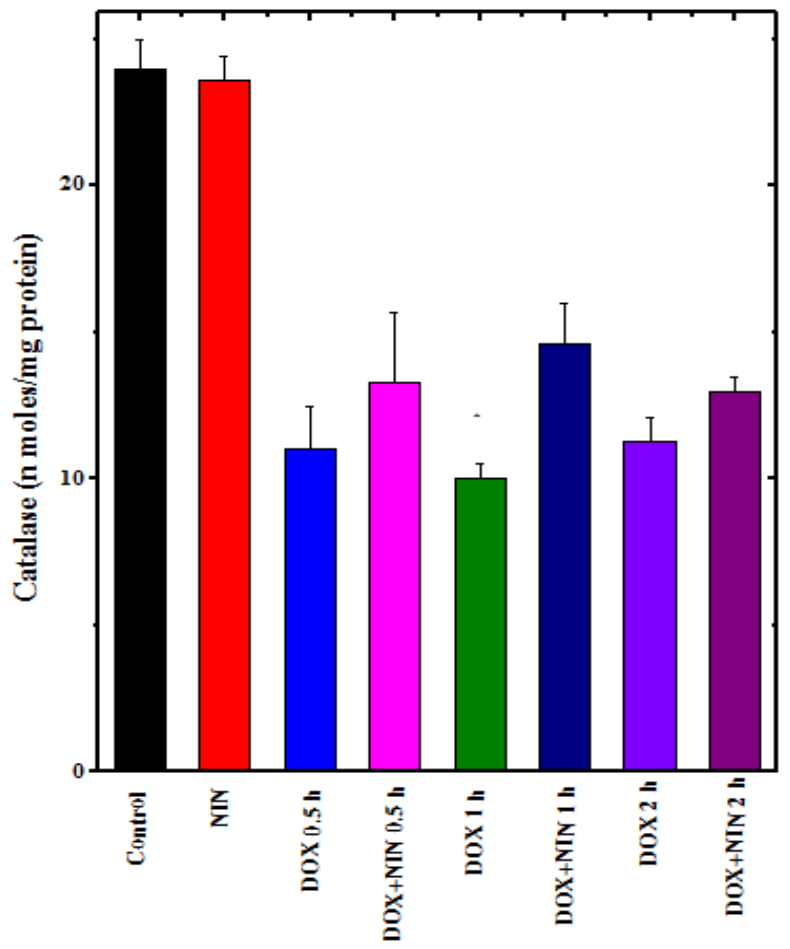

Figure 3 Alteration in the doxorubicin-induced decline in the catalase activity in the rat lung by naringin $\mathrm{p}<0.01$. 


\section{Superoxide dismutase}

The spontaneous superoxide dismutase activity in the rat lung was $19.6 \pm 0.3 \mathrm{nmol} / \mathrm{mg}$ protein and naringin treatment did not alter the spontaneous SOD activity significantly (Figure 4). The doxorubicin treatment alone significantly reduced the SOD activity at all postdoxorubicin-treatment assay times as compared to control. The doxorubicin treatment led to approximately 1.6 -fold reduction in the SOD activity when compared to the spontaneous SOD activity at all post-doxorubicin-treatment times. The naringin administration in the rats before doxorubicin administration marginally increased the SOD activity at all post doxorubicin treatment time when compared to doxorubicin treatment alone (Figure 4). However, this rise in SOD activity was not significant statistically (Figure 4).

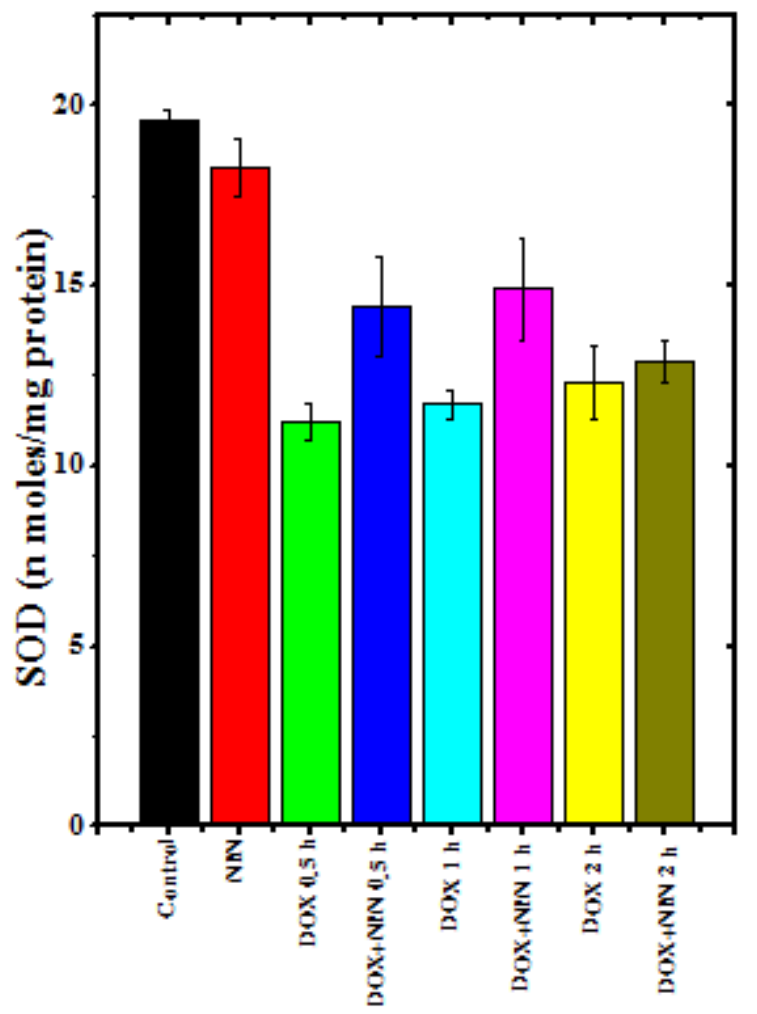

Figure 4 Alteration in the doxorubicin-induced depletion in the superoxide dismutase activity in the rat lung by naringin $\mathrm{p}<0.01$ when compared to control.

\section{Discussion}

Free radicals are produced in the organisms that use oxygen for their energy requirements and usually they are neutralized by the endogenous antioxidants in the cell. Free radicals are also needed for many physiological activities including regulation of immune function. ${ }^{50}$ Doxorubicin is an important antibiotic which finds it use in the treatment of several cancers either alone or in combination with other chemotherapeutic drugs. ${ }^{5}$ The optimum utilization of Doxorubicin is limited due to development of life threatening cardiotoxicity. ${ }^{10}$ Lungs play an important role in respiration and are essential in the sustenance of life. Pulmonary edema, pneumonitis or interstitial lung disease or lung fibrosis has been reported as one of the adverse side effects in cancer patients receiving doxorubicin alone or in combination with other chemotherapy drugs. ${ }^{51,52}$ This indicates that there is a need for the pharmacological agent/s that can reduce or prevent lung damage in the patients receiving Doxorubicin. Therefore, the present study was undertaken to investigate the protective effect of a dietary bioflavanone naringin in the lungs of rats treated with doxorubicin.

Glutathione or $\gamma$-glutamylcysteinylglycine (GSH) is a tripeptide thiol which is ubiquitously synthesized by all eukaryotic cells as a protective measure against the oxygen radical induced oxidative stress. ${ }^{53-55}$ It acts as a strong antioxidant and its depletion is associated with structural and functional disturbances in cells and rise in the oxidative stress. ${ }^{54,55}$ The doxorubicin administration reduced the GSH concentration in a time dependent manner and it reached a nadir at $2 \mathrm{~h}$ post- doxorubicin treatment. These results are in agreement with earlier reports where doxorubicin has been reported to reduce glutathione contents in rat liver and heart. ${ }^{32,56}$ The earlier studies on mice has also reported a decline in the GSH contents in the heart, liver and bone marrow cells. ${ }^{24,33,34,57}$ Naringin treatment arrested the doxorubicin decline in the rat lung in the present study. Earlier naringin has been reported to alleviate the doxorubicin-induced decline in the GSH concentration in rat liver and mouse liver and bone marrow cells. . $^{2433,34,58,59}$ The extract of Aegle mermelos has also been reported to increase the GSH contents in mice heart in an earlier study. ${ }^{57}$ An amino acid glutamine has been also reported to protect rats against Doxorubicin-induced attrition in GSH contents. ${ }^{56}$

Glutathione-S-transferases (GST) are synthesized by all organisms and they conjugate with GSH and different endogenous and exogenous electrophilic substances. They play an important role in cell proliferation and cell death and also detoxification and protection of DNA against a variety of toxic insults..$^{60,61}$ The enhanced expression of GST in cancer cells is linked to resistance to chemotherapy. ${ }^{62}$ The depletion of GST activity by doxorubicin in the rat lung may induce adverse side effects. Our findings of reduced GST activity are in conformation with earlier reports, where doxorubicin treatment has been reported to reduce GST activity in mice and rats. ${ }^{32-34,45}$ Treatment of rats with naringin reduced the doxorubicin -induced decline in GST activity and a similar effect has been observed earlier in mouse liver, bone marrow and heart. ${ }^{24,32-34,45}$

The main function of catalase enzymes is to neutralize hydrogen peroxide produced during respiration. These enzymes convert $\mathrm{H}_{2} \mathrm{O}_{2}$ into water and molecular oxygen. ${ }^{63}$ Their reduced activity increases accumulation of $\mathrm{H}_{2} \mathrm{O}_{2}$ and oxidative stress. The doxorubicin administration reduced the activity of catalase enzyme and lowest activities was observed at $2 \mathrm{~h}$ post- doxorubicin treatment. Doxorubicin treatment has been found to reduce catalase activity in the heart and liver of rats. ${ }^{32,59}$ Likewise, doxorubicin treatment has been reported to reduce catalase activity in bone marrow cells, heart and liver of mice..$^{24,33,34,57} \mathrm{Administration}$ of naringin in rats alleviated the doxorubicin-induced decline in the catalase activity and a similar effect has been observed in the liver and hearts of rats and mice bone marrow cells in earlier studies. ${ }^{24,32-34,58,59}$ The Aegle marmelos extract has been found to protect mice heart against the doxorubicin -induced depletion in the catalase activity. ${ }^{57}$

Superoxide dismutase enzymes (SOD) are synthesized by eukaryotic cells and are present inside the cell as well in the extracellular matrix ${ }^{64-66}$ The SODs also remove $\mathrm{H}_{2} \mathrm{O}_{2}$ generated during respiration and convert it into less harmful products like water and molecular oxygen ${ }^{67}$ doxorubicin treatment reduced the SOD activity 
in the rat lung in the present study. doxorubicin induces cardiotoxicity, nephrotoxicity and hepatotoxicity by interacting with eNOS and subsequently elevates the superoxide radical production that in turn induces toxic effects. ${ }^{68}$ This may be one of the reasons of reduced SOD activity in our study. The doxorubicin has been reported to deplete SOD activity in mice bone marrow, liver and heart earlier. ${ }^{24,33,34,57}$ Doxorubicin has also been found to reduce SOD activity in the rat liver. ${ }^{32}$ Naringin treatment alleviated the doxorubicin-induced decline in rat lungs however the increase in SOD activity in the lungs was not statistically significant, which may be due to the tissue specificity. Earlier reports have observed that naringin arrested the doxorubicininduced decline in the SOD activity in rat liver and heart and mice bone marrow, liver and heart. ${ }^{24,32-34,58,59} \mathrm{~A}$ similar observation has been made in mice heart receiving extract of Aegle mermelos before doxorubicin administration. ${ }^{57}$

The exact mechanism by which naringin alleviated the DOXinduced oxidative stress in rat lungs is not well understood. It is plausible that naringin may have employed several putative mechanisms to exert its action. Naringin has been reported to scavenge free radicals and this action would have added in the rise in the activities of various enzymes and GSH contents in doxorubicin treated rat lung. Since doxorubicin-induces free radical by stimulating NADPH oxidase system and naringin has been found to inhibit the activation of NADPH oxidase that may have subsequently reduced the free radical formation. ${ }^{69,70}$ The presence of iron has been reported to add in the formation of doxorubicin -induced free radicals and naringin has been reported to chelate iron that would have also aided in the higher amounts of oxidants in the rat lungs in the present study. ${ }^{31}$ Earlier studies have reported that naringin upregulated the gene expression of catalase, and SOD that may have also contributed to increased antioxidant status in the present study. ${ }^{29}$ The doxorubicin has been reported to suppress Nrf2 leading to the reduction in the endogenous antioxidants and naringin has been found to stimulate Nrf2 which may have contributed to higher antioxidant status in the rat lung in the present study. ${ }^{71}$

\section{Conclusion}

The treatment of rats with doxorubicin resulted in the reduction in the endogenous antioxidants in the lungs, whereas administration of naringin before DOX treatment elevated the antioxidants. The increase in antioxidants by naringin may be due to free radical scavenging, inhibition of NADH oxidase, iron chelation and upregulation of Nrf2 elements in the rat lungs.

\section{Acknowledgements}

This work was supported by a grant no. F4-10/2010(BSR) UGC from the University Grants Commission, New Delhi, India.

\section{Conflict of interest}

Authors do not have any conflict of interest statement to declare.

\section{References}

1. Arcamone F, Cassinelli G, Fantini G, et al. Adriamycin, 14-hydroxydaunomycin, a new antitumor antibiotic from S. peucetius var. caesius. Biotechnol Bioeng. 1969;11(6):1101-1110.

2. Weiss RB. The anthracyclines: will we ever find a better doxorubicin? Semin Oncol. 1992;19(6):670-686.
3. Quiles JL, Ochoa JJ, Huertas JR, et al. Olive oil and mitochondrial oxidative stress: studies on adriamycin toxicity, physical exercise and ageing. UK: CABI Publishing, Oxford; 2006:119-151.

4. Otterson GA, Villalona-Calero MA, Hicks W, et al. Phase I/II Study of inhaled doxorubicin combined with platinum-based therapy for advanced non-small cell lung cancer. Clin Cancer Res. 2010;16(8):2466-2473.

5. Volkova M, Russell R. Anthracycline cardiotoxicity: prevalence, pathogenesis and treatment. Curr Cardiol Rev. 2011;7(4):214-220.

6. Tam K. The roles of doxorubicin in hepatocellular carcinoma. ADMET \& DMPK. 2013;1(3):29-44.

7. Calvo E, Moreno V, Flynn M, et al. Antitumor activity of lurbinectedin (PM01183) and doxorubicin in relapsed small-cell lung cancer: results from a phase I study. Ann Oncol. 2017;28(10):2559-2566.

8. Lipshultz SE, Lipsitz SR, Kutok JL, et al. Impact of hemochromatosis gene mutations on cardiac status in doxorubicin-treated survivors of childhood high-risk leukemia. Cancer. 2013;119(19):3555-3562.

9. Tacar O, Sriamornsak P, Dass CR. Doxorubicin: an update on anticancer molecular action, toxicity and novel drug delivery systems. J Pharm Pharmacol. 2013;65(2):157-170.

10. Carvalho FS, Burgeiro A, Garcia R, et al. Doxorubicin-induced cardiotoxicity: from bioenergetic failure and cell death to cardiomyopathy. Med Res Rev. 2014;34(1):106-135.

11. Myers C. The role of iron in doxorubicin-induced cardiomyopathy. Semin Oncol. 1998;25(4 Supl 10):10-14.

12. Minotti G, Cairo G, Monti E. Role of iron in anthracycline cardiotoxicity: new tunes for an old song? FASEB J. 1999;13(2):199-212.

13. Ichikawa $\mathrm{Y}$, Ghanefar M, Wu R, et al. Cardiotoxicity of doxorubicin is mediated through mitochondrial iron accumulation. J Clin Invest. 2014;124(2):617-630.

14. Minotti G, Menna P, Salvatorelli E, et al. Anthracyclines: molecular advances and pharmacologic developments in antitumor activity and cardiotoxicity. Pharmacol Rev. 2004;56(2):185-229.

15. Tokarska-Schlattner M, Zaugg M, Zuppinger C, et al. New insights into doxorubicin-induced cardiotoxicity: the critical role of cellular energetics. J Mol Cell Cardiol. 2006;41(3):389-405.

16. Gianni L, Herman EH, Lipshultz SE, et al. Anthracycline cardiotoxicity: from bench to bedside. J Clin Oncol. 2008;26(22):3777-3784.

17. Mordente A, Meucci E, Silvestrini A, et al. New developments in anthracycline-induced cardiotoxicity. Curr Med Chem. 2009;16(13):1656-1672.

18. Octavia Y, Tocchetti CG, Gabrielson KL, et al. Doxorubicin-induced cardiomyopathy: from molecular mechanisms to therapeutic strategies. J Mol Cell Cardiol. 2012;52(6):1213-1225.

19. Gutteridge JMC, Halliwell B. Iron toxicity and oxygen radicals. Bailliere's Clin Haematol. 1989;2(2):195-256.

20. Swiader K, Lamer-Zarawska E. Flavonoids of rare artemisia species and their antifungal properties. Fitoterapia. 1996;67(1):77-78.

21. Gammal AA, Mansour RM. Antimicrobial activities of some flavonoid compounds. Zentrabl Mikrobiol. 1986;141(7):561-565.

22. Aboobaker VS, Balgi $\mathrm{AD}$, Bhattacharya RK. In vivo effect of dietary factors on the molecular action of aflatoxin B1: Role of non-nutrient phenolic compounds on the catalytic activity of liver fraction. In Vivo. 1994;8(6):1095-1098.

23. Gordon PB, Holen I, Seglen PO. Protection by naringin and some other flavonoids of hepatocytic autophagy and endocytosis against inhibition 
by okadaic acid. J Biol Chem. 1995;270(11):5830-5838.

24. Jagetia GC, Reddy TK. The grape fruit flavonone naringin protects mice against doxorubicin-induced cardiotoxicity. J Mol Biochem. 2014;3(1).

25. Kim HD, Jeong KH, Jung UJ, et al. Naringin treatment induces neuroprotective effects in a mouse model of Parkinson's disease in vivo, but not enough to restore the lesioned dopaminergic system. $J$ Nutr Biochem. 2016;28:140-146.

26. Russo A, Acquaviva R, Campisi A, et al. Bioflavonoids as antiradicals, antioxidants and DNA cleavage protectors. Cell Biol Toxicol. 2000;16(2):91-98.

27. Gorinstein S, Leontowicz H, Leontowicz M, et al. Effect of hesperidin and naringin on the plasma lipid profile and plasma antioxidant activity in rats fed a cholesterol-containing diet. J Sci Food Agric. 2007;87(17):1257-1262.

28. Jeon SM, Bok SH, Jang MK, et al. Antioxidative activity of naringin and lovastatin in high cholesterol-fed rabbits. Life Sci. 2001;69(24):2855-2866.

29. Jeon SM, Bok SH, Jang MK, et al. Comparison of antioxidant effects of naringin and probucol in cholesterol-fed rabbits. Clin Chim Acta. 2002;317(1-2):181-190

30. Jagetia GC, Venkatesha VA, Reddy TK. Naringin, a citrus flavonone, protects against radiation-induced chromosome damage in mouse bone marrow. Mutagenesis. 2003;18(4):337-343.

31. Jagetia GC, Reddy TK. Alleviation of iron induced oxidative stress by the grape fruit flavanone naringin in vitro. Chem Biol Interactions. 2011;190(2-3):121-128.

32. Jagetia GC, Lalnuntluangi V. The citrus flavanone naringin enhances antioxidant status in the albino rat liver treated with doxorubicin. Biochem Mol Biol J. 2016; 2(2):9.

33. Jagetia GC, Lalrinengi C. Naringin, a grape fruit bioflavonoid protects mice bone marrow cells against the doxorubicin-induced oxidative stress. SOJ Biochem. 2017;3(1):1-9.

34. Jagetia GC, Lalrinengi C. Treatment of mice with naringin alleviates the doxorubicin-induced oxidative stress in the liver of Swiss albino mice. MOJ Anat \& Physiol. 2017;4(2):00130.

35. Jagetia GC, Reddy TK. The grapefruit flavanone naringin protects against the radiation-induced genomic instability in the mice bone marrow: a micronucleus study. Mutat Res. 2002;519(1-2):37-48.

36. Jagetia GC, Reddy TK. The grape fruit bioflavonoid naringin protects against the doxorubicin-induced micronuclei formation in mouse bone marrow. Int J Mol Biol. 2016;1(1):00006.

37. You $\mathrm{Q}, \mathrm{Wu} \mathrm{Z}, \mathrm{Wu} \mathrm{B}$, et al. Naringin protects cardiomyocytes against hyperglycemia-induced injuries in vitro and in vivo. J Endocrinol. 2016;230(2):197-214.

38. Jagetia GC, Reddy TK. Chemopreventive effect of naringin on the benzo(a)pyrene-induced forestomach carcinoma in mice. Int Cancer Preven. 2004;1(6):429-444.

39. Kumar A, Dogra S, Prakash A. Protective effect of naringin, a citrus flavonoid, against colchicine-induced cognitive dysfunction and oxidative damage in rats. J Med Food. 2010;13(4):976-984.

40. Adebiyi OO, Adebiyi OA, Owira PM. Naringin reverses hepatocyte apoptosis and oxidative stress associated with HIV-1 nucleotide reverse transcriptase inhibitors-induced metabolic complications. Nutrients. 2015;7(12):10352-10368.

41. Turgut NH, Kara H, Elagoz S, et al. The protective effect of naringin against bleomycin-induced pulmonary fibrosis in Wistar rats. Pulm Med. 2016:7601393.

42. Ma X, Lv J, Sun S, et al. Naringin ameliorates bone loss induced by sciatic neurectomy and increases semaphorin $3 \mathrm{~A}$ expression in denervated bone. Sci Rep. 2016;6:24562.

43. Camargo CA, Gomes-Marcondes MC, Wutzki NC, et al. Naringin inhibits tumor growth and reduces interleukin- 6 and tumor necrosis factor $\alpha$ levels in rats with Walker 256 carcinosarcoma. Anticancer Res. 2012;32(1):129-133.

44. Li H, Yang B, Huang J, et al. Naringin inhibits growth potential of human triple-negative breast cancer cells by targeting $\beta$-catenin signalling pathway. Toxicol Lett. 2013; 220(3):219-228.

45. Zeng L, Zhen Y, Chen Y, et al. Naringin inhibits growth and induces apoptosis by a mechanism dependent on reduced activation of $\mathrm{NF} \kappa \mathrm{B} /$ COX 2 caspase-1 pathway in HeLa cervical cancer cells. Int J Oncol. 2014;45(5):1929-1936.

46. Moron MS, Depierre JW, Mannervik B. Levels of glutathione, glutathione reductase and glutathione S-transferase activities in rat lung and liver. Biochim Biophy Acta. 1979;582(1):67-78.

47. Habig WH, Pabst MJ, Jakoby WB. Glutathione S-transferases. The first enzymatic step in mercapturic acid formation. J Biol Chem. 1974;249(22):7130-7139.

48. Aebi H. Catalase in vitro. Methods Enzymol. 1984;105:121-126.

49. Marklund S, Marklund G. Involvement of the superoxide anion radical in the autooxidation of pyrogallol and a convenient assay for superoxide dismutase. Eur J Biochem. 1974;47(3):469-474.

50. McCord JM, Fridovich I. Superoxide dismutase: an enzymic function for erythrocuprein (hemocuprein). J Biol Chem. 1969;244(22):6049-6055.

51. Mazzotta M, Giusti R, Iacono D, et al. Pulmonary fibrosis after pegylated liposomal doxorubicin in elderly patient with cutaneous angiosarcoma. Case Rep Oncol Medi. 2016;2016:8034832.

52. Irfan O, Gilani JA, Irshad A, et al. Pharmacological threat to lungs: a case series and literature review. Cureus. 2017;9(5):e1232.

53. Meister A, Anderson ME. Glutathione. Ann Rev Biochem. 1983;52(1):711-760.

54. Lushchak VI. Glutathione homeostasis and functions: potential targets for medical interventions. J Amino Acids. 2012;2012:736837.

55. Schumacker PT. Reactive oxygen species in cancer: A dance with the devil. Cancer Cell. 2015;27(2):156-157.

56. Todorova VK, Kaufmann Y, Hennings L, et al. Oral glutamine protects against acute doxorubicin-induced cardiotoxicity of tumor-bearing rats. J Nutr. 2010;140(1):44-48.

57. Jagetia GC, Venkatesh P. An indigenous plant bael (Aegle marmelos (L.) Correa) extract protects against the doxorubicin-induced cardiotoxicity in mice. Biochem Physiol. 2015;4:3.

58. Papasani VMR, Hanumantharayappa B, Annapurna A. Cardioprotective effect of naringin against doxorubicin induced cardiomyopathy in rats. Indo American J Pharmaceut Res. 2014;4(5):2593-2598.

59. Kwatra M, Kumar V, Jangra A, et al. Ameliorative effect of naringin against doxorubicin-induced acute cardiac toxicity in rats. Pharm Biol. 2016;54(4):637-647.

60. Laborde E. Glutathione transferases as mediators of signalling pathways involved in cell proliferation and cell death. Cell Death Differ. 2010;17(9):1373-1380. 
61. Schnekenburger M, Karius T, Diederich M. Regulation of epigenetic traits of the glutathione -S-transferase P1 gene: from detoxification toward cancer prevention and diagnosis. Front Pharmacol. 2014;5:170.

62. McIlwain CC Townsend DM, Tew KD. Glutathione S-transferase polymorphisms: cancer incidence and therapy. Oncogene. 2006;25(11):1639-1648.

63. Kodydková J, Vávrová L, Kocík M, et al. Human catalase, its polymorphisms, regulation and changes of its activity in different diseases. Folia Biol (Praha). 2014;60(4):153-167.

64. Fattman CL, Schaefer LM, Oury TD. Extracellular superoxide dismutase in biology and medicine. Free Radic Biol Med. 2003;35(3):236-256.

65. Miller AF. Superoxide dismutases: Ancient enzymes and new insights. FEBS Letters. 2012;586(5):585-595.

66. Carillon J, Rouanet JM, Cristol JP, et al. Superoxide dismutase administration, a potential therapy against oxidative stress related diseases: Several routes of supplementation and proposal of an original mechanism of action. Pharm Res. 2013;30(11):2718-2728.

67. Perry JJ, Shin DS, Getzoff ED, et al. The structural biochemistry of the superoxide dismutases. Biochim Biophys Acta. 2010;1804(2):245-262.

68. Vasquez-Vivar J, Martasek $\mathrm{P}, \operatorname{Hogg} \mathrm{N}$, et al. Endothelial nitric oxide synthase-dependent superoxide generation from adriamycin. Biochemistry. 1997;36(38):11293-11297.

69. Gilleron M, Marechal X, Montaigne D, et al. NADPH oxidases participate to doxorubicin-induced cardiac myocyte apoptosis. Biochem Biophys Res Commun. 2009;388(4):727-731.

70. Li W, Wang C, Peng J, et al. Naringin inhibits TNF- $\alpha$ induced oxidative stress and inflammatory response in HUVECs via Nox4/NF- $\kappa \mathrm{B}$ and PI3K/Akt pathways. Curr Pharm Biotechnol. 2014;15(12):1173-1182.

71. Kulasekaran G, Ganapasam S. Neuroprotective efficacy of naringin on 3-nitropropionic acid-induced mitochondrial dysfunction through the modulation of Nrf2 signaling pathway in PC12 cells. Mol Cell Biochem. 2015;409(1-2):199-211. 